\title{
The Third Residential Scientific Conference for Senior Registrars in Psychiatry*
}

\author{
Ola JunaID, Senior Registrar in Psychiatry, Department of Health Care of the Elderly, \\ Queen's Medical Centre, Nottingham NG7 2UH
}

The conference started with a 'keynote' address by Professor Eve Johnstone entitled 'How to Succeed in Academic Psychiatry'. Professor Johnstone provided a stark picture for academic psychiatry present and future. She reminded us that disadvantages of an academic career included lack of tenure, poor conditions of service relative to NHS clinicians, lack of independence, limited amount of free time, the unavailability of private practice, and envy from other academics who are paid less. She also pointed out that in effect academics have two "full-time" jobs. Careers go through phases, and the most productive phase is often under 40 , but a career lasts until 65. On the other hand, advantages included meeting people in exotic places, and the opportunity, if lucky, to become famous. This was a fascinating and informative insight into the world of academic psychiatry.

The rest of the conference was devoted to workshops. There were day long workshops on effective presentations skills, witness skills, and managing your first day as a consultant. Dr Greg Richardson, Consultant Child Psychiatrist, Lime Trees Adolescent Unit, York, conducted the workshop 'Managing your first day as a consultant'. Significantly, this group of experienced senior registrars actively seeking consultant posts had a long list of worries and concerns. These included the inability to predict the

*Held at Heriot-Watt University, Edinburgh from 26-28 March 1992. effect of current NHS reforms on the jobs available, the need to deal with resistance to change, replacing well-known and loved previous consultants, the need to feel liked $v$. the need to achieve respect from colleagues and members of teams, the ability to deal with negotiating and contracting, the ability to determine and acquire necessary resources, and the fear of taking on too much and overextending oneself. At the end of the workshop some of these worries and fears were allayed.

On the final day there were half-day workshops on research methodology, getting your consultant post, and writing scientific papers. Ralph Footring, Scientific Editor, British Journal of Psychiatry, provided inside information on the techniques necessary to get your scientific paper published. He reminded us that it is necessary to answer the following questions: why write?; what do you have to say?; who do you want to say it to?; and who will be interested? He took us through the editing process and explained the various stages up to printing. He ended by providing valuable tips on how to impress the editor.

Feedback at the plenary session revealed that the format of workshops provided an interactive medium for learning about information that is not taught or made available in formal sessions from the various rotations around the country. The meeting also provided the opportunity for senior registrars from all over the country in various specialities to meet, compare notes, establish relationships, and possibly even plant the seeds for future collaboration.

\section{Gender identity and development in childhood and adolescence}

\author{
R. P. SNAITH, Senior Lecturer in Psychiatry, St James's University Hospital, \\ Leeds LS9 7TF
}

A two-day conference on this topic was held on 13 and 14 March 1992 at St George's Hospital, London. The theme is the inspiration of $\mathrm{Dr}$
Domenico Di Ceglie who, with colleagues in the Child and Adolescent Psychiatry Department at St George's and Croydon Child Guidance Clinic, has 